\title{
Periodontitis and Rheumatoid Arthritis in Sub-Saharan Africa, Gaps and Way Forward: A Systematic Review and Meta-Analysis
}

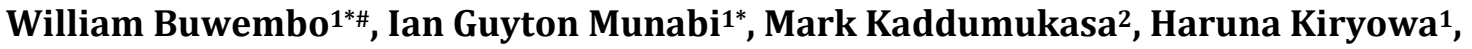 \\ Ethel Nankya ${ }^{3}$, William Evan Johnson?3 ${ }^{3}$ Emmy Okello², Nelson Sewankambo²

\begin{abstract}
${ }^{1}$ Department of Human Anatomy, School of Biomedical Sciences, Makerere University College of Health Sciences, Kampala, Uganda

${ }^{2}$ Department of Medicine, School of Medicine, Makerere University College of Health Sciences, Kampala, Uganda ${ }^{3}$ Division of Computational Biomedicine, Boston University School of Medicine, Boston University, Boston, MA, USA Email: "wbuwembo@chs.mak.ac.ug, imunabi@chs.mak.ac.ug, mkaddumukasa@chs.mak.ac.ug, kiryowa2005@yahoo.com, etnankya@bu.edu,wej@bu.edu,emmyoks@gmail.com, sewankam@infocom.co.ug
\end{abstract}

How to cite this paper: Buwembo, W., Munabi, I.G., Kaddumukasa, M., Kiryowa, H., Nankya, E., Johnson, W.E., Okello, E. and Sewankambo, N. (2019) Periodontitis and Rheumatoid Arthritis in Sub-Saharan Africa, Gaps and Way Forward: A Systematic Review and Meta-Analysis. Open Journal of Stomatology, 9, 215-226. https://doi.org/10.4236/ojst.2019.910023

Received: August 13, 2019

Accepted: October 7, 2019

Published: October 10, 2019

Copyright $\odot 2019$ by author(s) and Scientific Research Publishing Inc. This work is licensed under the Creative Commons Attribution International License (CC BY 4.0).

http://creativecommons.org/licenses/by/4.0/

\begin{abstract}
Background: This review identified papers that described periodontitis and rheumatoid arthritis in sub-Saharan Africa. Only English language publications from January 2010 to December 2017 describing original research in sub-Saharan Africa on the association between periodontitis and rheumatoid arthritis were considered for this study. Methods: Published databases: PubMed, Science direct and Google scholar, were searched using terms "periodontitis", "rheumatoid arthritis" and "Sub-Saharan Africa" to generate a set of putative studies. Articles with data on both rheumatoid arthritis and periodontitis compared to controls were selected. Studies on the association of periodontitis with cardiovascular disease, arthritis or rheumatoid arthritis alone were excluded. Data were extracted, critically appraised, and analyzed using a random-effect Mantel-Haenszel meta-analysis on plaque index, gingival index, pocket depth and clinical attachment loss. Results: Three publications were selected for the systematic review and 2 for the meta-analysis. Two studies were from Sudan, and one was from Burina Faso. There was a significant increase in pocket depth (mean difference: $0.31 ; 95 \%$ CI: 0.21 , $0.41 ; \mathrm{N}=274 ;(\mathrm{p} \leq 0.001))$ and clinical attachment loss (mean difference: 0.47; 95\% CI: $0.22,0.75 ; \mathrm{N}=274$; $(\mathrm{p} \leq 0.001)$ ) in participants with rheumatoid arthritis compared to normal controls. Conclusion: Findings from these combined studies show a significant relationship between periodontal disease and rheumatoid arthritis with increased periodontal pocket depth and clinical attachment loss. They also highlight the need for additional work especially in
\end{abstract}

*These authors contributed equally to this work. 
the area of associating rheumatoid arthritis with $P$. gingivalis, the oral microbiome and treating periodontal diseases to help in the management of rheumatoid arthritis.

\section{Keywords}

Periodontitis, Rheumatoid Arthritis, Sub-Saharan Africa

\section{Introduction}

Periodontitis (PD) is characterized by destruction of both soft and hard tissue surrounding the teeth [1]. Rheumatoid arthritis (RA) is characterized by destruction of cartilage and bone in the joints, mediated by similar bone-resorptive cytokines and proteinases [2] [3]. Both diseases lead to significant morbidity, with PD ultimately leading to tooth loss and loss of masticatory function, while RA leads to loss of joint function and loss of mobility [4].

PD and RA share numerous similarities in pathogenesis, risk factors, and epidemiological associations [5]. They both share several immunological and morphological features including: increased pro-inflammatory cytokines and metalloproteinases [6]. Various hypotheses have been proposed that suggest that PD may potentially exacerbate or initiate RA or vice versa. One of the widely accepted hypotheses is that Porphyromonus gingivalis, a bacterium present in the oral cavity, induces breakdown of tolerance by exerting an abnormal post-translational protein modification called citrullination [4]. In citrullination the amino acid arginine is converted into citrulline after protein synthesis, resulting in a change of structure and function of the affected protein. The Porphyromonus gingivalis bacteria are thought to produce these citrullinated proteins with the aid of peptidyl-arginine-deiminases (PAD), enzymes that catalyze the conversion of peptidyl-arginine sections of proteins to peptidyl-citrulline. This leads to loss of tolerance to neo-epitopes eliciting a response that may result in disease [7].

Previous work in developed countries has shown that the occurrence and severity of periodontitis are higher among subjects with RA, showing a positive correlation between these two chronic inflammatory diseases [8] [9] [10]. In RA patients, periodontitis is a strong predictor of anti-citrullinated peptide antibodies (ACPA), which in part supports the observed higher RA disease activity scores of individuals with a correspondingly high burden of periodontal symptoms [11]. Several studies have evaluated the effect of periodontal treatment on RA and biomarkers of the disease [12] [13]. Studies have shown that, after non-surgical periodontal treatment, there is reduction of disease activity score on 28 joints (DAS28) in RA patients with PD. This was also associated with significant reductions in erythrocyte sedimentation rate and a trend towards a reduction in TNF- $\alpha$ titers and DAS scores [14]. The control of local periodontal infection and inflammation by non-surgical periodontal therapy may attenuate the systemic inflammatory response leading to an improvement in RA disease 
activity [15] [16].

Ongoing studies in the developed countries continue to unravel the different pathogenic linkages and possible treatment remedies between these two diseases [13] [15] [17]. In Sub-Saharan Africa (which is associated with poor oral hygiene) where these two diseases also occur, little is known about this link and possible benefits of co-treating PD and RA. This review addresses the question: what is the association between PD and RA among Sub-Saharan African patients?

\section{Methods}

\subsection{Search Strategy}

We searched the following published databases: PubMed, Science direct and Google scholar [18]. We placed date restrictions to identify articles published between Jan 2010 to Dec 2017. Only English language articles were selected. Articles were searched for using the search terms ((Chronic Periodontitis) OR (Periodontitis, Chronic) OR (Periodontitis, Chronic) OR (Adult Periodontitis) OR (Periodontitis, Adult)) AND ((Rheumatoid arthritis) OR (Arthritis, rheumatoid) OR (subSaharan Africa) OR (Africa)). Studies with both diseased and controls were included. Studies looking at association of periodontal disease with the oral microbiome, cardiovascular disease, arthritis or rheumatoid arthritis alone were excluded from the study. In addition, those with unavailable abstracts were also excluded. The titles and abstracts of each citation were independently reviewed by three authors (EN, HK and IGM) and verified by a forth (WB). Full texts of potentially eligible papers, were independently reviewed by three authors $(\mathrm{MK}$, IGM, and WB) with consensus made through discussion on final study eligibility (See Figure 1). The Preferred Reporting Items for Systematic Reviews and Meta-Analyses (PRISMA) strategy was followed.

\subsection{Data Extraction}

Data were entered into a data extraction table from the full text articles of the included papers (Table 1). These included number of participants, age, gender, country of origin and periodontitis measures. These periodontitis measurements included percentages with periodontitis, probing depth, plaque index, missing teeth, proportion of sites with plaque, bleeding on probing (BOP), and clinical attachment loss (CAL). Two authors independently extracted all the data with any disagreements addressed through discussion.

\subsection{Critical Appraisal}

All included studies were assessed using the Downs and Black critical appraisal tool for non-randomized controlled trials [19]. This 27-item critical appraisal tool assesses study quality (10 items), external validity (3 items), study bias (7 items), confounding and selection bias (6 items), and power of the study (1 item). All papers were independently assessed by two reviewers (EN, HK) and verified by two reviewers (IGK and WB). 


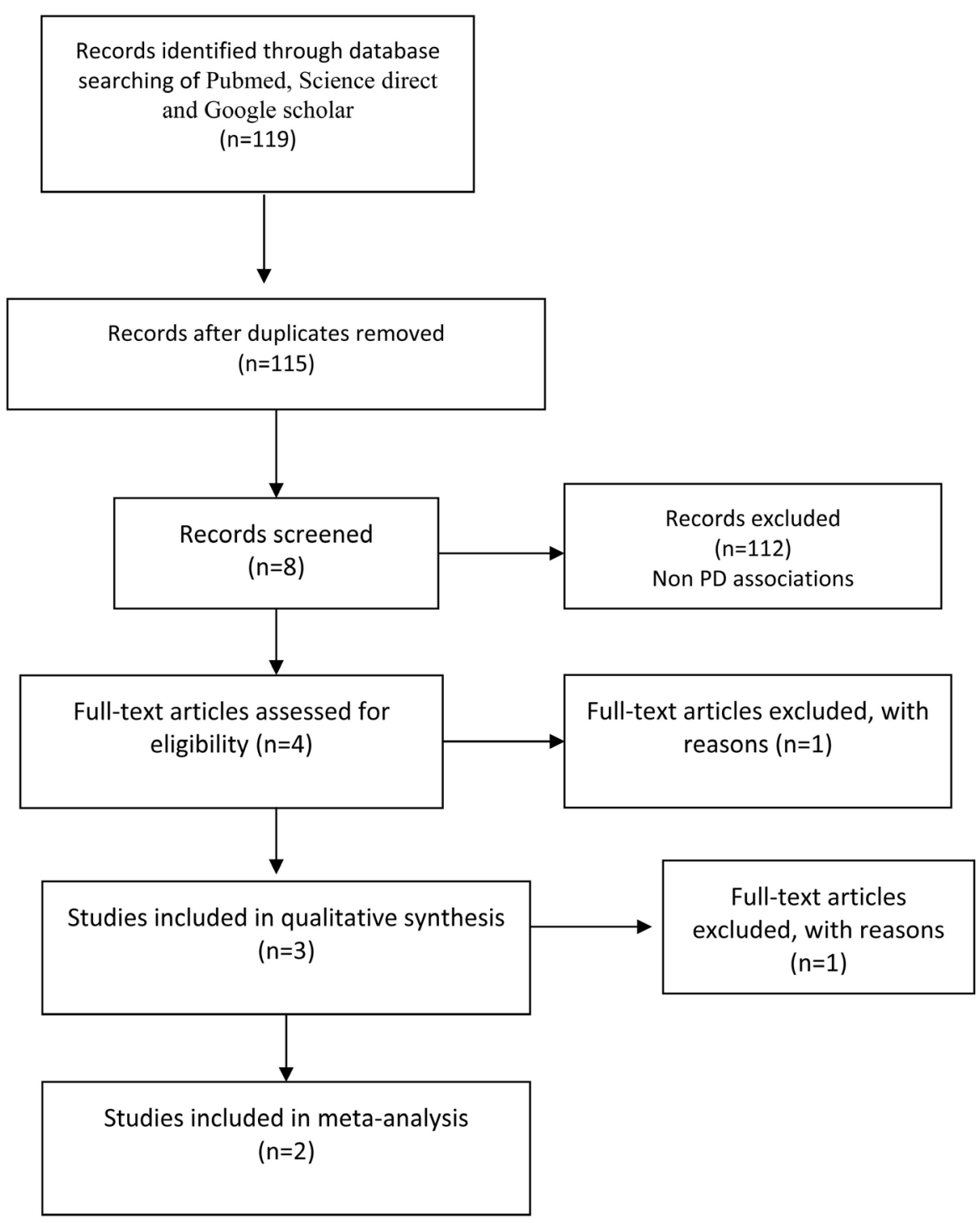

Figure 1. Literature review flow diagram.

\subsection{Data Analysis}

Study heterogeneity was assessed through visual assessment of the data extraction table (Table 1). As there was sufficient homogeneity in participant characteristics (Table 2), periodontal assessment, and study design, a meta-analytic approach was undertaken. The primary analysis was to estimate the mean difference between plaque index, gingival index, Pocket depth and CAL scores of periodontitis with rheumatoid arthritis over participants without rheumatoid arthritis. A fixed-effect Mantel-Haenszel meta-analysis was used when the inconsistency value $\mathrm{I}^{2}$ was $50 \%$ or less and $\mathrm{Chi}^{2}$ equated $\mathrm{p} \geq 0.10$. A random-effect Mantel-Haenszel meta-analysis was undertaken when $\mathrm{I}^{2}$ was $>50 \%$ and $\mathrm{Chi}^{2}$ equated to $\mathrm{p}<0.10$. All analyses were calculated with $95 \%$ confidence intervals, and forest-plots were constructed, and performed using R statistical computing software version 3.2.0 (Vienna, Austria) [20]. 
Table 1. Data extraction table for the systematic review.

\begin{tabular}{|c|c|c|c|}
\hline & $\begin{array}{l}\text { BMC Research Notes } \\
\text { 2011, 4:460 [22] }\end{array}$ & $\begin{array}{l}\text { Joint Bone Spine } \\
84,(2017) ; 113-114[21]\end{array}$ & $\begin{array}{l}\text { BMC Research Notes } \\
\text { 2017, 10:34 [23] }\end{array}$ \\
\hline Study design & Case-control & Case-control & Case-control \\
\hline Participant number & 160 & 129 & 171 \\
\hline Cases: Controls & $80: 80$ & $43: 86$ & $57: 57: 57$ \\
\hline Age & $\begin{array}{l}\text { Cases: Controls } \\
\text { Both: } 20 \text { - } 60 \text { years }\end{array}$ & $\begin{array}{c}\text { Cases: Controls } \\
46.5: 46.3\end{array}$ & $\begin{array}{l}\text { RA: PD: Control } \\
\text { 42.9:42:30.5 }\end{array}$ \\
\hline Gender & F:M 9:1 & $\begin{array}{l}\text { Females were } 79 \% \text { and } 75.6 \% \text { in the } \\
\text { cases and controls respectively. }\end{array}$ & $\mathrm{F}: \mathrm{M} 8.3: 1$ \\
\hline Country of origin & Sudan & Burkina Faso & Sudan \\
\hline Inclusion criteria & 2010-ACR/EULAR criteria for RA & 2010-ACR/EULAR criteria for RA & 2010-ACR/EULAR criteria for RA \\
\hline Exclusion criteria & $\begin{array}{l}\text { Pregnancy, lactation, smoking, periodontal } \\
\text { therapy or antibiotics in the previous three } \\
\text { months, or any systemic condition which } \\
\text { might have affected the progression of } \\
\text { periodontitis, localized or generalized } \\
\text { aggressive periodontitis }\end{array}$ & $\begin{array}{l}\text { Diabetes mellitus, pregnancy, } \\
\text { antibiotic therapy and smoking }\end{array}$ & $\begin{array}{l}\text { Systemic diseases that can affect } \\
\text { periodontal status, smoking, antibiotic } \\
\text { therapy with the last } 3 \text { months and } \\
\text { periodontal treatment with in the last } \\
6 \text { months }\end{array}$ \\
\hline Major findings & $\begin{array}{c}\text { No association between the drugs used for } \\
\text { treatment of rheumatoid arthritis (Non } \\
\text { Steroidal Anti-Inflammatory Drugs \& } \\
\text { Disease Mordifying Anti-Rheumatic } \\
\text { Drugs) and the periodontal parameters } \\
\text { (plaque index, gingival index, and clinical } \\
\text { attachment loss). }\end{array}$ & $\begin{array}{c}\text { Periodontal disease was not } \\
\text { significantly associated with Age } \geq 50 \\
\text { years, male gender, Disease duration } \geq \\
10 \text { years, DAS } 28 \geq 3.2 \text {, Joint } \\
\text { deformities and ACPA }\end{array}$ & $\begin{array}{l}\text { The was a significant difference in all } \\
\text { periodontal parameters among the } \\
\text { three groups. The periodontal disease } \\
\text { group experienced significantly higher } \\
\text { values in all clinical periodontal } \\
\text { parameters in comparison to the RA } \\
\text { and healthy groups }(\mathrm{p} \leq 0.001) .\end{array}$ \\
\hline
\end{tabular}

Table 2. Downs and Black critical appraisal results.

\begin{tabular}{|c|c|c|c|c|c|c|c|c|c|c|c|c|c|c|c|c|c|c|c|c|c|c|c|c|c|c|c|}
\hline & 1 & 2 & 3 & 4 & 5 & 6 & 7 & 8 & 9 & 10 & 11 & 12 & 13 & 14 & 15 & 16 & 17 & 18 & 19 & 20 & 21 & 22 & 23 & 24 & 25 & 26 & 27 \\
\hline \multicolumn{28}{|l|}{ Reference } \\
\hline $\begin{array}{l}\text { Abdelsa- } \\
\text { lam }\end{array}$ & $\checkmark$ & $\checkmark$ & $\checkmark$ & $\mathrm{N}$ & $\checkmark$ & $\checkmark$ & $\checkmark$ & $\mathrm{N}$ & $\mathrm{N}$ & $\checkmark$ & $\mathrm{X}$ & $\mathrm{X}$ & $\mathrm{N}$ & $\mathrm{N}$ & $\mathrm{N}$ & $\checkmark$ & $\mathrm{N}$ & $\checkmark$ & $\mathrm{N}$ & $\mathrm{N}$ & $\checkmark$ & $\mathrm{X}$ & $\mathrm{N}$ & $\mathrm{N}$ & $\mathrm{N}$ & $\mathrm{N}$ & $\checkmark$ \\
\hline Gamel & $\checkmark$ & $\checkmark$ & $\checkmark$ & $\mathrm{N}$ & $\checkmark$ & $\checkmark$ & $\checkmark$ & $\mathrm{N}$ & $\mathrm{N}$ & $\checkmark$ & $\mathrm{X}$ & $\mathrm{X}$ & $\mathrm{N}$ & $\mathrm{N}$ & $\mathrm{N}$ & $\checkmark$ & $\mathrm{N}$ & $\checkmark$ & $\mathrm{N}$ & $\mathrm{N}$ & $\checkmark$ & $\mathrm{X}$ & $\mathrm{N}$ & $\mathrm{N}$ & $\mathrm{N}$ & $\mathrm{N}$ & $\checkmark$ \\
\hline
\end{tabular}

Key: $\checkmark$, satisfied; X, not satisfied; N, not applicable. (1) Hypotheses/aims/objectives clearly stated; (2) Main outcome measures clearly described. (3) Characteristics of patients/subjects clearly described. (4) Interventions of interest clearly described. (5) Distribution of principal confounders in each group clearly described. (6) Main findings clearly described. (7) Estimates of random variability in the data provided. (8) Important adverse events reported. (9) Characteristics of patients lost to follow-up described. (10) Actual probability values reported. (11) Participants approached representative of entire population. (12) Participants recruited representative of entire population. (13) Staff, places, and facilities representative of majority of population. (14) Blinding of study subjects. (16) Blinding of assessors. (16) Data based on data-dredging clearly stated. (17) Adjustment of different length of follow-up or duration between case and control. (18) Appropriate statistical tests used. (19) Compliance to intervention reliable. (20) Main outcome measure reliable and valid. (21) Intervention groups or case-controls recruited from same population. (22) Intervention groups or case-controls recruited at the same time. (23) Study subjects randomized to the interventions. (24) Was concealed randomization to allocation undertaken. (25) Adequate adjustment made in the analysis of confounders. (26) Patient losses accounted for. (27) Sufficiently powered cohort size.

\section{Results}

\subsection{Overall Description of the African Publications}

Three publications met the inclusion criteria (Figure 1). Two of the studies were from Sudan and one from Burkina Faso. All the studies had a comparative study design, that included RA and PD, and controls. There were 129 participants in 
the Burkina Faso study, 160 and 171 participants in the first and second Sudan studies respectively (Table 1 ).

\subsection{Age and Sex Predisposition}

In the Burkina Faso study [21] the mean age was $46.50 \pm 12.75$ years in the 43 cases and $46.39 \pm 14.39$ years in the 86 controls $(P=0.966)$. Females were more common in both cases and controls (79\% vs. $75.6 \%)$. The first Sudanese study [22] had 80 cases and 80 controls with an age range of 20 to 60 years. Again, there were more female (90\%) participants. The second Sudanese study [23] had 57 RA, 57 chronic periodontitis patients and 57 healthy adult participants. The mean age was similar in the RA and chronic periodontitis groups (42.9 \pm 10.3$)$ and $(42.0 \pm 10.0)$ years, respectively. However, a younger age was found in the control group $(30.51 \pm 6.00)$ years.

\subsection{Periodontitis Measures}

The mean number of times participants brushed their teeth per day was $1.30 \pm$ 0.46 in the cases and $1.43 \pm 0.56$ in the controls $(P=0.201)$ from Burkino Faso [21]. The first Sudanese study [22] revealed no significant differences in plaque and gingival index among study and control groups, with mean plaque index of $(1.25 \pm 0.4)$ for patients and $(1.17 \pm 0.28)$ for the control group $(\mathrm{p}=0.360)$. The mean gingival index was $(1.2 \pm 0.24)$ for the patients and $(1.2 \pm 0.33)$ for the control $(p=0.305)$. The results showed statistically significant differences in clinical attachment loss between study and control groups, with mean clinical attachment loss of $(1.03 \pm 0.95)$ for the study group and $(0.56 \pm 0.63)$ for the control group ( $\mathrm{p} \leq 0.001)$. On the other hand, the prevalence of periodontal disease in the study from Burkino Faso [21] was $83.72 \%(36 / 43)$ in the cases and $54.65 \%(47 / 86)$ in the controls. The odds ratio (OR) for periodontal disease among the cases compared to the controls was 4.26 (95\% confidence interval, $1.71-10.64 ; \mathrm{p} \leq 0.001)$.

In the third study included in this analysis from Sudan [23], clinical periodontal measurements were analyzed in two steps: first, the full mouth recordings at six sites/tooth were compared between the study groups; then the levels of salivary TNF- $\alpha$ were compared among the three study groups. The results revealed a significant difference in all periodontal parameters among the three groups. The periodontal disease group had significantly higher values in all clinical periodontal parameters in comparison to the RA and healthy groups ( $\mathrm{p} \leq$ $0.001)$. The mean level of salivary TNF- $\alpha$ levels in the RA patients was (30.80 \pm 26.73) $\mathrm{pg} / \mathrm{ml}$ while in the chronic periodontitis patients and control subjects was $(28.70 \pm 35.24) \mathrm{pg} / \mathrm{ml}$ and $(35.98 \pm 30.43) \mathrm{pg} / \mathrm{ml}$ respectively. When comparing the salivary levels of TNF- $\alpha$ among the 3 study groups using one-way ANOVA test, no significant difference was detected $(\mathrm{p}=0.846)$. No significant correlation was found between the salivary level of TNF- $\alpha$ and CAL in the chronic periodontitis and RA groups. 


\subsection{Association of Periodontitis with RA Drugs}

Thirty-six of the study participants $(83.72 \%)$ were taking methotrexate while three participants (6.98\%) were receiving both methotrexate and sulfasalazine for the treatment of rheumatoid arthritis in the Burkino Faso study [21]. For the second study from Sudan [22] no association was found between the type of drug used to treat rheumatoid arthritis (NSAIDs \& DMARDs) and the periodontal parameters (plaque index, gingival index, and clinical attachment loss). This was a similar result to the findings from the third study also from Sudan [23], where the medications used by the RA patients were methotrexate, hydroxychloroquine, prednisolone, NSAID and sulphasalazine and there was no significant correlation between the type of drug used for treatment of RA and the clinical attachment loss (CAL). Additionally, no significant difference was obtained when correlating the CAL with the disease duration $(\mathrm{p}=0.189)$.

\subsection{Meta-Analysis of Two Studies}

Two studies were included in the meta-analysis [22] [23], because the third study [21] did not break down the periodontal measures into plaque index, gingival index, Pocket depth and CAL scores and was hence not comparable. There were significant differences in pocket depth (mean difference: $0.31 ; 95 \%$ CI: 0.21 to $0.4 ; \mathrm{N}=274(\mathrm{p} \leq 0.001)$ ) and clinical attachment loss (mean difference: 0.47 ; 95\% CI: 0.22 to $0.75 ; \mathrm{N}=274$ ( $\mathrm{p} \leq 0.001)$ ) in participants with RA compared to normal controls. The plaque index (mean difference: 0.38 ; $95 \%$ CI: -0.21 to 0.97 ; $\mathrm{N}=274$ ) and gingival index (mean difference: 0.36 ; $95 \% \mathrm{CI}:-0.35$ to $1.08: \mathrm{N}=$ 274) were not significantly different (Figure 2).

\section{Discussion}

In this review, we set out to determine the association between PD and RA among African Sub-Saharan (SSA) patients. We found that only three studies

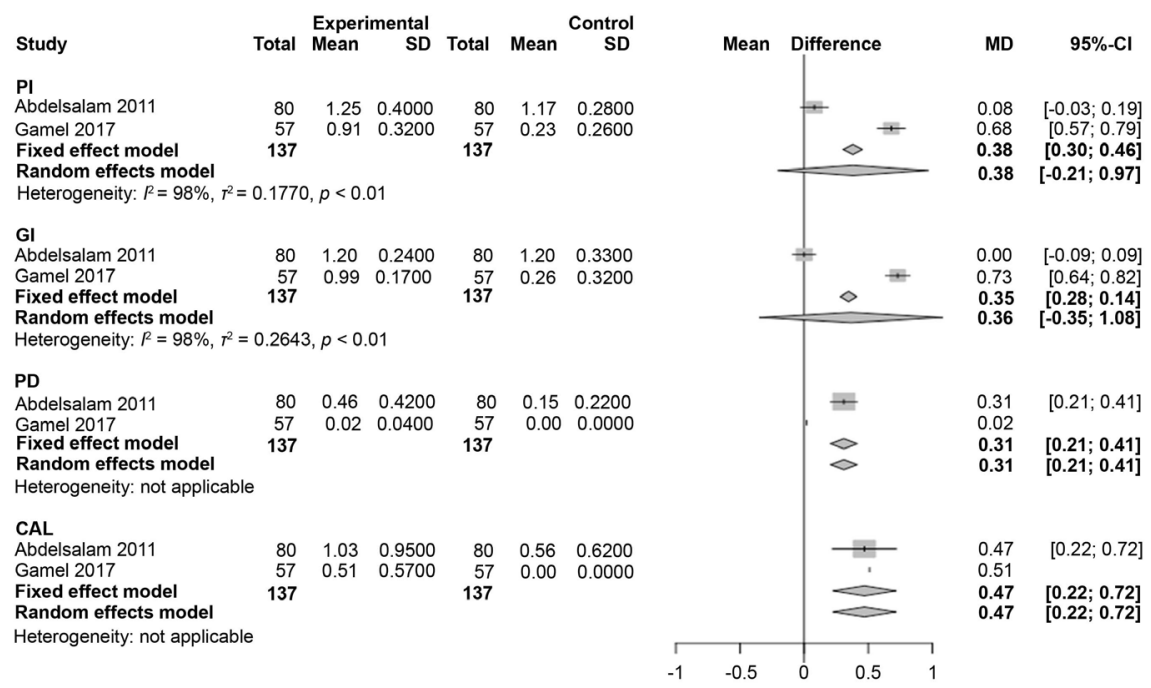

Figure 2. Meta analysis Forest plot. SD: Standard deviation, MD: Mean difference. 
had been conducted in SSA and they reported that periodontal disease (PD) was more frequently observed in participants with Rheumatoid Arthritis (RA) as compared to healthy controls [21] [22] [23]. This is in agreement with findings from high income countries studies which have demonstrated an association between PD and RA [4] [24] [25]. These studies and the meta-analysis conducted here showed that pocket depth and clinical attachment loss is greater in RA participants than non-RA participants [25]. Also, consistent with previous reports in the current review is the absence of any associations linking periodontal disease to other parameters (gender, disease duration, DAS28, deformities, and ACPA) [21].

The association between RA and PD via micro-organisms has long been postulated [26]. Specifically $P$. gingivalis has been suggested as the possible link and has been studied [27] in other areas outside sub-Saharan Africa. In the current review this association with $P$. gingivalis is glaringly missing in the African studies and needs to be explored. Also, several studies have examined the effects of periodontal treatment on the DAS 28 score, a common measure of RA activity [28]. They have reported that after non-surgical periodontal treatment for three months or six months: the DAS 28 levels, serum erythrocyte sedimentation rate, CRP and tumor necrosis factor (TNF)- $\alpha$ were statistically lower [29]. Only one study mentions inflammatory markers [23]. These findings are also missing from these African studies and need to be explored [30].

There is scarcity of information regarding the interaction of these two diseases to guide the formulation of interventions or educational programs. Several studies have demonstrated that the human microbiome is important in maintaining health, for example dysbiosis has been associated with various diseases [31] [32] Thus, translational studies of the microbiome will have the potential for clinical and diagnostic use. With the populations of Sub-Saharan Africa on the rise with anticipated increase in the numbers of rheumatoid arthritis patients, development of interventional strategies is urgently needed to address this. Further studies are needed in understanding the oral microbiome and its relationship with non-communicable diseases especially RA in Sub-Saharan Africa.

\section{Limitations}

The current literature search included studies published from 2010 to 2017. Hence, we may not have identified all pertinent articles, and our search and review strategy may have introduced some bias. Additionally, we included only English-language articles, which may have led to missing articles written in other languages. We could not include clinical trials because they were not available, which could reduce the power of the conclusions made from our review. Finally, there were only a limited number of studies comparing periodontitis with rheumatoid arthritis from the wider Sub-Saharan African region, the two studies included in the meta-analysis were from one country Sudan, which may limit ge- 
neralization of the findings to the entire continent.

\section{Conclusion}

The findings from these studies from sub-Saharan Africa show a significant relationship between periodontal disease and RA in terms of pocket depth and clinical attachment loss. However, there is no significant difference between plaque and gingival index among study and control groups. These studies highlight the potential of studying the relationship between these two diseases in sub-Saharan Africa and the lack of work especially in the area of associating RA with $P$. gingivalis and treating periodontal diseases to help in the management of RA.

\section{Acknowledgements}

WB was supported by Grant Number D43TW010132 supported by Office of the Director, National Institutes of Health (OD), National Institute of Dental \& Craniofacial Research (NIDCR), National Institute of Neurological Disorders And Stroke (NINDS), National Heart, Lung, And Blood Institute (NHLBI), Fogarty International Center (FIC), National Institute on Minority Health and Health Disparities (NIMHD). Its contents are solely the responsibility of the authors and do not necessarily represent the official views of the supporting offices.

\section{Authors' Contributions}

EO conceived the initial research idea and was a major contributor to the manuscript. WB, IGM and KM refined the research idea, drafted the initial propos$\mathrm{al}$, and were involved in the whole research process till drafting of the manuscript. WEJ and NS were instrumental in refining the research methodology, contributed to the drafting of the manuscript and were involved in analyzing the data for meta-analysis. HK and EN contributed to data extraction for the systemic review and critically read the draft manuscript. All co-authors reviewed the final manuscript prior to submission.

\section{Conflicts of Interest}

The authors declare that they have no competing interests.

\section{References}

[1] Kornman, K.S. (2008) Mapping the Pathogenesis of Periodontitis: A New Look. Journal of Periodontology, 79, 1560-1568. https://doi.org/10.1902/jop.2008.080213

[2] Rosenstein, E.D., Greenwald, R.A., Kushner, L.J. and Weissmann, G. (2004) Hypothesis: The Humoral Immune Response to Oral Bacteria Provides a Stimulus for the Development of Rheumatoid Arthritis. Inflammation, 28, 311-318. https://doi.org/10.1007/s10753-004-6641-z

[3] Schett, G. and Teitelbaum, S.L. (2009) Osteoclasts and Arthritis. Journal of Bone and Mineral Research, 24, 1142-1146. https://doi.org/10.1359/jbmr.090533

[4] Payne, J.B., Golub, L.M., Thiele, G.M. and Mikuls, T.R. (2015) The Link between 
Periodontitis and Rheumatoid Arthritis: A Periodontist's Perspective. Current Oral Health Reports, 2, 20-29. https://doi.org/10.1007/s40496-014-0040-9

[5] Scher, J.U., Ubeda, C., Equinda, M., Khanin, R., Buischi, Y., Viale, A., Lipuma, L., Attur, M., Pillinger, M.H., Weissmann, G., et al. (2012) Periodontal Disease and the Oral Microbiota in New-Onset Rheumatoid Arthritis. Arthritis \& Rheumatology, 64, 3083-3094. https://doi.org/10.1002/art.34539

[6] Liu, X., Zou, Q., Zeng, B., Fang, Y. and Wei, H. (2013) Analysis of Fecal Lactobacillus Community Structure in Patients with Early Rheumatoid Arthritis. Current Microbiology, 67, 170-176. https://doi.org/10.1007/s00284-013-0338-1

[7] Kozarov, E.V., Dorn, B.R., Shelburne, C.E., Dunn, W.A. and Progulske-Fox, A. (2005) Human Atherosclerotic Plaque Contains Viable Invasive Actinobacillus actinomycetemcomitans and Porphyromonas gingivalis. Arteriosclerosis, Thrombosis, and Vascular Biology, 25, e17-e18. https://doi.org/10.1161/01.ATV.0000155018.67835.1a

[8] Joseph, R., Rajappan, S., Nath, S.G. and Paul, B.J. (2013) Association between Chronic Periodontitis and Rheumatoid Arthritis: A Hospital-Based Case-Control Study. Rheumatology International, 33, 103-109.

https://doi.org/10.1007/s00296-011-2284-1

[9] Wolff, B., Berger, T., Frese, C., Max, R., Blank, N., Lorenz, H.M. and Wolff, D. (2015) Oral Status in Patients with Early Rheumatoid Arthritis: A Prospective, Case-Control Study. Rheumatology (Oxford), 53, 526-531. https://doi.org/10.1093/rheumatology/ket362

[10] Fuggle, N.R., Smith, T.O., Kaul, A. and Sofat, N. (2016) Hand to Mouth: A Systematic Review and Meta-Analysis of the Association between Rheumatoid Arthritis and Periodontitis. Frontiers in immunology, 7, 80. https://doi.org/10.3389/fimmu.2016.00080

[11] Mikuls, T.R., Thiele, G.M., Deane, K.D., Payne, J.B., O’Dell, J.R., Yu, F., Sayles, H., Weisman, M.H., Gregersen, P.K., Buckner, J.H., et al. (2012) Porphyromonas gingivalis and Disease-Related Autoantibodies in Individuals at Increased Risk of Rheumatoid Arthritis. Arthritis \& Rheumatology, 64, 3522-3530. https://doi.org/10.1002/art.34595

[12] Kaur, S., Bright, R., Proudman, S.M. and Bartold, P.M. (2014) Does Periodontal Treatment Influence Clinical and Biochemical Measures for Rheumatoid Arthritis? A Systematic Review and Meta-Analysis. Seminars in Arthritis and Rheumatism, 44, 113-122. https://doi.org/10.1016/j.semarthrit.2014.04.009

[13] Yang, N.Y., Wang, C.Y., Chyuan, I.T., Wu, K.J., Tu, Y.K., Chang, C.W., Hsu, P.N., Kuo, M.Y. and Chen, Y.W. (2017) Significant Association of Rheumatoid Arthritis-Related Inflammatory Markers with Non-Surgical Periodontal Therapy. Journal of the Formosan Medical Association, 117, 1003-1010. https://doi.org/10.1016/j.jfma.2017.11.006

[14] Pinho Mde, N., Oliveira, R.D., Novaes, A.B. and Voltarelli, J.C. (2009) Relationship between Periodontitis and Rheumatoid Arthritis and the Effect of Non-Surgical Periodontal Treatment. Brazilian Dental Journal, 20, 355-364. https://doi.org/10.1590/S0103-64402009000500001

[15] Gavrilă, B.I., Ciofu, C. and Stoica, V. (2016) Biomarkers in Rheumatoid Arthritis, What Is New? JMed Life, 9, 144-1448.

[16] Okada, M., Kobayashi, T., Ito, S., Yokoyama, T., Abe, A., Murasawa, A. and Yoshie, H. (2013) Periodontal Treatment Decreases Levels of Antibodies to Porphyromonas gingivalis and Citrulline in Patients with Rheumatoid Arthritis and Periodontitis. 
Journal of Periodontology, 84, e74-e84. https://doi.org/10.1902/jop.2013.130079

[17] Calderaro, D.C., Correa, J.D., Ferreira, G.A., Barbosa, I.G., Martins, C.C., Silva, T.A. and Teixeira, A.L. (2016) Influence of Periodontal Treatment on Rheumatoid Arthritis: A Systematic Review and Meta-Analysis. Revista Brasileira de Reumatologia, 57, 238-244. https://doi.org/10.1016/j.rbre.2016.11.011

[18] Haddaway, N.R., Collins, A.M., Coughlin, D. and Kirk, S. (2015) The Role of Google Scholar in Evidence Reviews and Its Applicability to Grey Literature Searching. PLoS ONE, 10, e0138237. https://doi.org/10.1371/journal.pone.0138237

[19] Downs, S.H. and Black, N. (1998) The Feasibility of Creating a Checklist for the Assessment of the Methodological Quality Both of Randomised and Non-Randomised Studies of Health Care Interventions. Journal of Epidemiology and Community Health, 52, 377-384. https://doi.org/10.1136/jech.52.6.377

[20] R Core Team: R (2015) A Language and Environment for Statistical Computing. 3.2.0 Edition, R Foundation for Statistical Computing, Vienna.

[21] Ouedraogo, D.D., Tiendrebeogo, J., Guiguimde, P.L., Nikiema, P.I., Ouedraogo, D., Kabore, F., Zongo, E. and Hayem, G. (2017) Periodontal Disease in Patients with Rheumatoid Arthritis in Sub-Saharan Africa: A Case-Control Study. Joint, Bone, Spine: Revue du Rhumatisme, 84, 113-114. https://doi.org/10.1016/j.jbspin.2016.02.014

[22] Abdelsalam, S.K., Hashim, N.T., Elsalamabi, E.M. and Gismalla, B.G. (2011) Periodontal Status of Rheumatoid Arthritis Patients in Khartoum State. BMC Research Notes, 4, 460. https://doi.org/10.1186/1756-0500-4-460

[23] Gamel, E.B., Hashim, N.T., Satti, A. and Gismalla, B.G. (2017) Salivary TNFalpha Levels in Groups of Subjects with Rheumatoid Arthritis and Chronic Periodontitis. BMC Research Notes, 10, 34. https://doi.org/10.1186/s13104-016-2341-7

[24] Koziel, J., Mydel, P. and Potempa, J. (2014) The Link between Periodontal Disease and Rheumatoid Arthritis: An Updated Review. Current Rheumatology Reports, 16, 408. https://doi.org/10.1007/s11926-014-0408-9

[25] Kaur, S., White, S. and Bartold, P.M. (2013) Periodontal Disease and Rheumatoid Arthritis: A Systematic Review. Journal of Dental Research, 92, 399-408. https://doi.org/10.1177/0022034513483142

[26] Bender, P., Burgin, W.B., Sculean, A. and Eick, S. (2017) Serum Antibody Levels against Porphyromonas gingivalis in Patients with and without Rheumatoid Arthritis-A Systematic Review and Meta-Analysis. Clinical Oral Investigations, 21, 33-42. https://doi.org/10.1007/s00784-016-1938-5

[27] Kumar, P.S. (2017) From Focal Sepsis to Periodontal Medicine: A Century of Exploring the Role of the Oral Microbiome in Systemic Disease. The Journal of Physiology, 595, 465-476. https://doi.org/10.1113/JP272427

[28] Prevoo, M.L., van’t Hof, M.A., Kuper, H.H., van Leeuwen, M.A., van de Putte, L.B. and van Riel, P.L. (1995) Modified Disease Activity Scores That Include Twenty-Eight-Joint Counts. Development and Validation in a Prospective Longitudinal Study of Patients with Rheumatoid Arthritis. Arthritis and Rheumatism, 38, 44-48. https://doi.org/10.1002/art.1780380107

[29] Erciyas, K., Sezer, U., Ustun, K., Pehlivan, Y., Kisacik, B., Senyurt, S.Z., Tarakcioglu, M. and Onat, A.M. (2013) Effects of Periodontal Therapy on Disease Activity and Systemic Inflammation in Rheumatoid Arthritis Patients. Oral Diseases, 19, 394-400. https://doi.org/10.1111/odi.12017

[30] Araujo, V.M., Melo, I.M. and Lima, V. (2015) Relationship between Periodontitis 
and Rheumatoid Arthritis: Review of the Literature. Mediators of inflammation, 2015, Article ID: 259074. https://doi.org/10.1155/2015/259074

[31] Cho, I. and Blaser, M.J. (2012) The Human Microbiome: At the Interface of Health and Disease. Nature Reviews Genetics, 13, 260-270. https://doi.org/10.1038/nrg3182

[32] Pflughoeft, K.J. and Versalovic, J. (2012) Human Microbiome in Health and Disease. Annual Review of Pathology, 7, 99-122.

https://doi.org/10.1146/annurev-pathol-011811-132421 